Т. В. Смірнова, О. М. Дрєєв, О. А. Смірнов

Центральноукраїнський національний технічний університет, Кропивницький, Україна

\title{
ЕКСПЕРТНА СИСТЕМА ОПТИМІЗАЦЇ̈ ПРОЦЕСУ ВІДНОВЛЕННЯ ТА ЗМЦЦЕННЯ ПОВЕРХОНЬ ДЕТАЛЕЙ ТИПУ «ВАЛ» ЕЛЕКТРОДУГОВИМ НАПИЛЕННЯМ
}

\begin{abstract}
Предметом вивчення у статті є побудова експертної системи оптимізації процесу відновлення та зміцнення поверхонь деталей типу «ВАЛ» електродуговим напиленням. Метою роботи $\epsilon$ побудова експертної системи оптимізації процесу відновлення та зміцнення поверхонь деталей типу «вал» електродуговим напиленням у вигляді хмарної рекомендаційної системи як сервісу (SaaS) з отримання поверхонь валів зі сталі 45 із заданими характеристиками на основі комбінації декількох технологічних процесів. Задачі: синтезувати абстрактний технологічний процес, визначити його властивості та методи переходу до конкретного технологічного процесу; сформулювати інформаційну модель технологічного процесу та методи іiі отримання; побудувати абстрактні експертні системи та їх складові для оптимізації процесу відновлення та зміцнення поверхонь деталей типу «вал» електродуговим напиленням. Результатами роботи $\epsilon$ експертна система, яка включає у себе: базу знань, що містить дані експериментів, допустимі діапазони вхідних даних, список вхідних параметрів, список вихідних параметрів, методи та математичне забезпечення розрахунків витрат на процес; систему отримання вимог до результатів відновлення та критерій (або критерії) оптимізації; система пошуку екстремумів в багатовимірному просторі; систему перевірки на досягнення результату; систему виявлення “зацикленості” пошуку розв'язків, у випадках недосяжності поставлених вимог; систему введення неконтрольованих вхідних параметрів (в вказаній системі не використано, тому що устаткування має контрольоване середовище обробки); систему забезпечення інформаційного потоку між компонентами експертної системи з урахуванням синхронізації та взаємних блокувань. Висновки: наукова новизна полягає у сукупності синтезованого абстрактного технологічного процесу, визначення його властивостей та методів переходу до конкретного технологічного процесу; сформульованої інформаційної моделі технологічного процесу та методів іiі отримання, що дозволило побудувати абстрактні експертні системи та їх складові для оптимізації процесу відновлення та зміцнення поверхонь деталей типу «вал» електродуговим напиленням у вигляді хмарної рекомендаційної системи як сервісу (SaaS).
\end{abstract}

Keywords: експертна система, інформаційні процеси, прийняття рішень, поверхня, відновлення, зміцнення, сталь.

\section{Вступ}

Сучасні лінії відновлення та зміцнення поверхонь деталей працюють в умовах гнучкої зміни параметрів проведення технологічних операцій. Тобто у таких умовах, коли самі технологічні процеси (ТП) відновлення та зміцнювання поверхонь, у свою чергу можуть змінюватися іншими технологіями відновлення та зміцнення в залежності від видів пошкодження поверхонь деталей та від умов їх експлуатації. В той час, як активно розроблюються інформаційні системи підтримки прийняття рішень для забезпечення оптимізації окремих ТП [1], систем для вирішення задачі побудови оптимізованого ланцюга ТП, з вибором більш оптимального процесу серед альтернативних за задачею, не вистачає [2]. Крім того $з$ розвитком комп'ютерних технологій, зростає актуальність використання хмарних технологій в реалізації інформаційних систем. У даній роботі пропонується використати для оптимізації ТП хмарну рекомендаційну систему як сервіс (SaaS). SaaS - програмне забезпечення як послуга, одна 3 форм хмарних обчислень, модель обслуговування, при якій підписникам надається готове прикладне програмне забезпечення, яке повністю обслуговується провайдером. Постачальник в цій моделі самостійно управляє застосунком, надаючи замовникам доступ до функцій з клієнтських пристроїв, як правило через мобільний додаток або веббраузер. Основна перевага моделі $\mathrm{SaaS}$ для споживача послуги полягає у відсутності витрат, пов'яза- них з установкою, оновленням і підтримкою працездатності обладнання і працюючого на ньому програмного забезпечення. На основі зазначених актуальних проблем в інформаційному забезпеченні експертних систем оптимізації ланцюга ТП, нами поставлена мета.

Мета роботи: побудувати експертну систему оптимізації процесу відновлення та зміцнення поверхонь деталей типу «вал» електродуговим напиленням у вигляді хмарної рекомендаційної системи як сервісу (SaaS) з отримання поверхонь валів зі сталі 45 із заданими характеристиками на основі комбінації декількох технологічних процесів. Для досягнення поставленої мети необхідно визначити види та область застосування експертних та рекомендаційних систем для забезпечення оптимізації ланцюга технологічних процесів.

\section{Абстрактний технологічний процес, його властивості та методи переходу до конкретного технологічного процесу}

Пошук оптимальних рішень при проектуванні ТП з кількох операцій відновлення зношених поверхонь валів має ряд особливостей. Технологічний процес має складатися 3 ланцюга окремих технологічних операцій (ТО), коли кожна з операцій за різних причин може бути замінена на ТО на іншій основі, але аналогічну за отриманим результатом. Тобто, кожна операція ТП: підготовка поверхні, відновлення, механічна обробка, зміцнення поверхні створює ланцюг ТО, де кожна операція має можли- 
вість бути виконаною за допомогою кількох альтернативних технологій. Для кожного з етапів обробки характерна технологічна спадковість, коли використання технологій обробки залежить від обмежень, які накладено попередньою використаною операцією. Проблемою $є$ часткова технологічна спадковість, коли кожні наступні операції частково перекривають кілька попередніх ТО, що значно усклад- нює повний граф можливих ланцюгів проведених операцій.

У зв'язку з цим оптимізація процесу відновлення та зміцнення деталей $є$ неможливою до визначення повного ланцюга обробки [2].

Для оптимізації ТО з ланцюга ТП запропоновано використовувати експертні системи (ЕС), загальна структура яких показана на рис. 1.

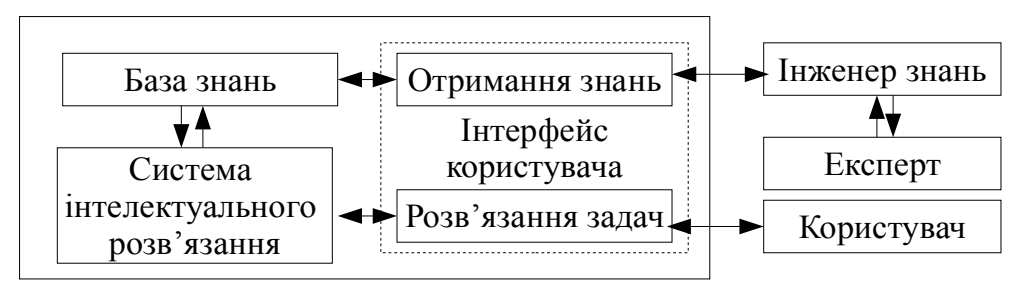

Рис. 1. Абстрактна експертна система [3]

До наведеного абстрактного представлення ЕС належать такі різновиди експертних систем: семантичні; фреймові; продукційні; нейрономережні.

У схемі використано такі позначення:

- експерт - фахівець 3 даної ТО;

- інженер знань - фахівець, який формалізує знання експертів, відповідає за процес отримання знань та надання їх до бази знань ЕC;

- база знань - множина доступних знань що до обраної ТО;

- система інтелектуального розв'язання ключовий елемент ЕC, який на основі наявних знань та вхідних параметрів поставленої задачі надає параметри ТП з оптимізацією за заданими критеріями (час роботи, доступні матеріали, сукупні грошові витрати);

- інтерфейс користувача відповідає за взаємодію між комп'ютерними системами та людиною.

Розглянемо ЕС на основі об'єктного підходу за класифікацією методів представлення знань (рис. 2):

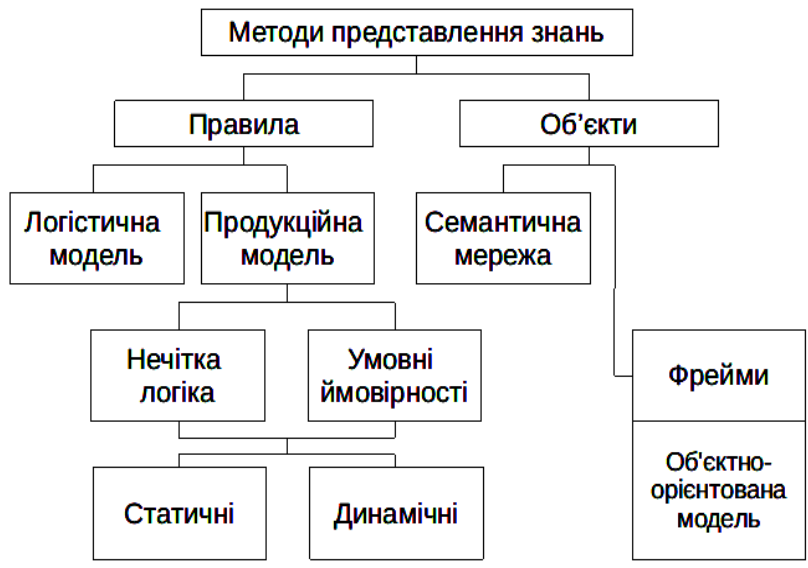

Рис. 2. Методи представлення знань в експертних системах

Семантичні експертні системи оперують сутностями та їх атрибутами. Атрибут може мати кількісні характеристики, що відокремлюється до класу властивостей сутностей. Технологічні операції мають сутності у вигляді технічної деталі, коли в процесі відновлення атрибути цієї деталі потрібно перенести 3 вхідного діапазону значень до заданих параметрів. Також сутностями до ТО є технологічні інструменти, коли для проведення обробки обираються саме ті, що мають відповідні атрибути із визначеними значеннями цих атрибутів. В процесі рішення система повинна враховувати зношуваність інструментальної бази, відповідно враховувати й вартість інструментів до остаточної вартості проведених операцій. Формально семантичний елемент $\mathrm{C}_{\mathrm{i}}$ можна представити таким чином:

$$
C_{i}=\left\langle N_{i}, S_{i,} p_{i}\right\rangle, S_{i} \subset S,
$$

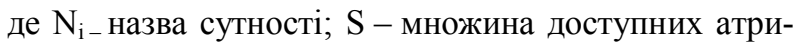

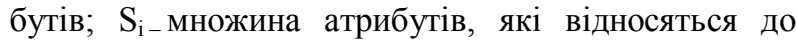
конкретної сутності.

Один атрибут може належати кільком сутностям; $\mathrm{p}_{\mathrm{i}}$ - кількісна характеристика атрибуту (якщо вона $є)$. До недоліків вказаної ЕС можна віднести ускладнену структуру бази знань, коли система атрибутів не є фіксованою, і може істотно змінюватися від сутності до сутності. Сукупність сутностей та атрибутів може утворювати складні графи залежностей, які описувати в стандартних таблицях релятивних базах даних не зручно.

Фреймові експертні системи є подальшим розвитком семантичної ЕС та більше нагадує об'єктний метод опису бази знань. Фрейми формують ієрархію об'єктів, які вони представляють. Фрейм складається 3 каркасу груп даних - слотів. В якості слотів можуть виступати факти, фрейми нижчі за ієрархією, умови застосування дій та дії, які можуть виконуватися над даними. Формально фрейм може бути представлений таким чином:

$$
F_{i}=\left\langle N_{i}, S_{1 i}, S_{2 i}, S_{3 i}\right\rangle,
$$

де $N$ - назва фрейму; $S_{1}$ - множина фактів, які визначають декларативну семантику фрейму; $S_{2}-$ множина зв'язків, які вказують на інші фрейми; $S_{3}-$ множина перетворень, які визначають функціональну семантику фрейму.

Фрейми мають спільні риси з об'єктно-орієнтованим методом представлення знань. Спільними рисами є спадковість фреймів, наявність фреймузразку - аналогу віртуальних класів або інтерфейсів, фрейм-екземпляр - аналог об'єкту, який є екземпля- 
ром класу. Завдяки декларативності та одночасно функціональності фреймових та об'єктно-орієнтованих методів надання знань, ця модель має значну універсальність, також до функціональних можливостей фреймів можна включити математичні регресійні моделі та моделі основані на нейронних мережах та нечіткій логіці. Тому, з причини максимальної відповідності до семантики з предметної області, для опису ТП можна надати перевагу фреймам.

\section{Інформаційна модель технологічного процесу та методи ії отримання}

В процесі побудови ЕС оптимізації ТП потрібно пройти наступні етапи:

1. Визначення вхідних-вихідних даних.

2. Складання словника атрибутів, які притаманні обраній ТО.

3. Виявлення об'єктів та понять.

4. Виявлення зв'язків між вхідними керованими та не керованими параметрами ТО.

5. Визначення цілей оптимізації.

6. Визначення стратегій визначення параметрів ТО для досягнення поставлених оптимізаційних задач.

Сформулюємо інформаційну модель ТП на основі відновлення та зміцнення поверхні електродуговим покриттям. Модель дозволяє отримати інформацію для розрахунку характеристик які отримуються в результаті обробки. При побудові математичної моделі ТП зазвичай обмежуються представленням об'єкту дослідження у вигляді “чорного ящика”. В результаті виникає потреба у функціональному пов'язуванні вхідних даних та визначених некерованих величин до параметрів, які вимагаються від ТП. Для електродугового напилення (ЕДН), як і для більшості ТП, така функціональна залежність матиме наступний вигляд:

$$
\vec{Y}=f(\overrightarrow{X, V, Z}, \vec{R}),
$$

де $\vec{X}$ - контрольовані величини процесу, для цих величин існують обмеження $x_{\min , i} \leq x_{i} \leq x_{\max , i} ; \vec{V}-$ відомі але не контрольовані величини процесу; $\vec{Z}$ - невідомі та не контрольовані величини; $\vec{R}-$ випадкові величини, що впливають на процес; $\vec{Y}$ параметри, які досягаються в процесі технологічної обробки.

Випадкова складова є не контрольованою, тому в моделях часто ними нехтують, але в процесі оцінювання адекватності моделі обов'язково робиться пошук надійних інтервалів очікуваних величин 3 реальними результатами.

Для ЕДН величини які задають режим ТП показані в табл. 1.

В результаті багатофакторного експерименту 3 регресією результатів на степеневий поліном маємо математичну модель ТП, наприклад, для міцності зчеплення (2):
Таблиия 1 - Параметри, які задаються при проведенні електродугового напилення

\begin{tabular}{|c|l|c|l|}
\hline № & \multicolumn{1}{|c|}{ Назва параметру } & $\begin{array}{c}\text { Позна- } \\
\text { чення }\end{array}$ & \multicolumn{1}{c|}{$\begin{array}{c}\text { Допустимі } \\
\text { межі }\end{array}$} \\
\hline 1 & Напруга дуги & $\mathrm{x}_{1}$ & $\mathrm{U}=28 . .34 \mathrm{~B}$ \\
\hline 2 & Дистанція напилення & $\mathrm{x}_{2}$ & $\mathrm{~L}=80 . .200$ мм \\
\hline 3 & Діаметр дроту & $\mathrm{x}_{3}$ & $\mathrm{~d}=1,2 . .2,2$ мм \\
\hline 4 & Товщина покриття & $\mathrm{x}_{4}$ & $\mathrm{~h}=0,5 . .3,0$ мм \\
\hline 5 & Тиск в камері & $\mathrm{x}_{5}$ & $\mathrm{P}=2 . .10 \mathrm{MПа}$ \\
\hline 6 & Швидкість ковзання & $\mathrm{x}_{6}$ & $\mathrm{~V}=2,0 . .2,75 \mathrm{~m} / \mathrm{c}$ \\
\hline
\end{tabular}

$$
\begin{aligned}
y_{2}= & 94,5537-16,1578 \cdot x_{1}+8,66664 \cdot x_{2}- \\
& -4,37462 \cdot x_{3}-17,2747 \cdot x_{4}- \\
& -3,92423 \cdot x_{5}-16,0642 \cdot x_{6}- \\
& -17,0532 \cdot x_{2} \cdot x_{6}-22,4759 \cdot x_{3} \cdot x_{6}- \\
& -9,99573 \cdot x_{4} \cdot x_{6}+1,41499 \cdot x_{5} \cdot x_{6}
\end{aligned}
$$

До величин, які відносяться до множини результату технологічного процесу можна включити наступні параметри (табл. 2).

\section{Таблиия 2 - Параметри, які потрібно отримати в результаті обробки $\vec{Y}$}

\begin{tabular}{|l|c|c|c|}
\hline № & $\begin{array}{c}\text { Назва } \\
\text { параметру }\end{array}$ & $\begin{array}{c}\text { Позна- } \\
\text { чення }\end{array}$ & Отримані межі \\
\hline 1 & Пористість & $\mathrm{y}_{1}$ & $<10 \%$ \\
\hline 2 & $\begin{array}{c}\text { Міцність } \\
\text { зчеплення }\end{array}$ & $\mathrm{y}_{2}$ & $\sigma=30 . .70 \mathrm{MПа}$ \\
\hline 3 & Твердість & $\mathrm{y}_{3}$ & $6900 . .73000 \mathrm{MПа}$ \\
\hline 4 & Зносостійкість & $\mathrm{y}_{4}$ & $\mathrm{~J}_{\mathrm{h}}=11 . .15 \mathrm{мкм/км}\left(10^{-12}\right)$ \\
\hline
\end{tabular}

Для інших вихідних параметрів також маємо математичні регресійні відношення або правила їх знаходження.

Множина відношень (1) та за типом (2) складають математичну модель ТП.

Надалі побудова ЕС вимагає наявності відношень для знаходження параметрів які оптимізуються, наприклад: грошові витрати, час обробки та витрачений сирцевий ресурс відповідно:

$$
G(\vec{Y}), T(\vec{Y}), E(\vec{Y}), \ldots
$$

На основі математичної моделі ТП (2) та відношень рахування витрат на ТП (3) автором побудована ЕС оптимізації ТП електродугового напилення сталі на поверхні валів 3 метою їх відновлення та зміцнення (рис. 3) [4].

Схема передбачає наявність ітераційного пошуку методом поступового покращення результату 3 початкового припустимого режиму роботи системи. Для більш надійного результату, при наявності значної нелінійності, такий процес можна проводити з кількох початкових точок. 


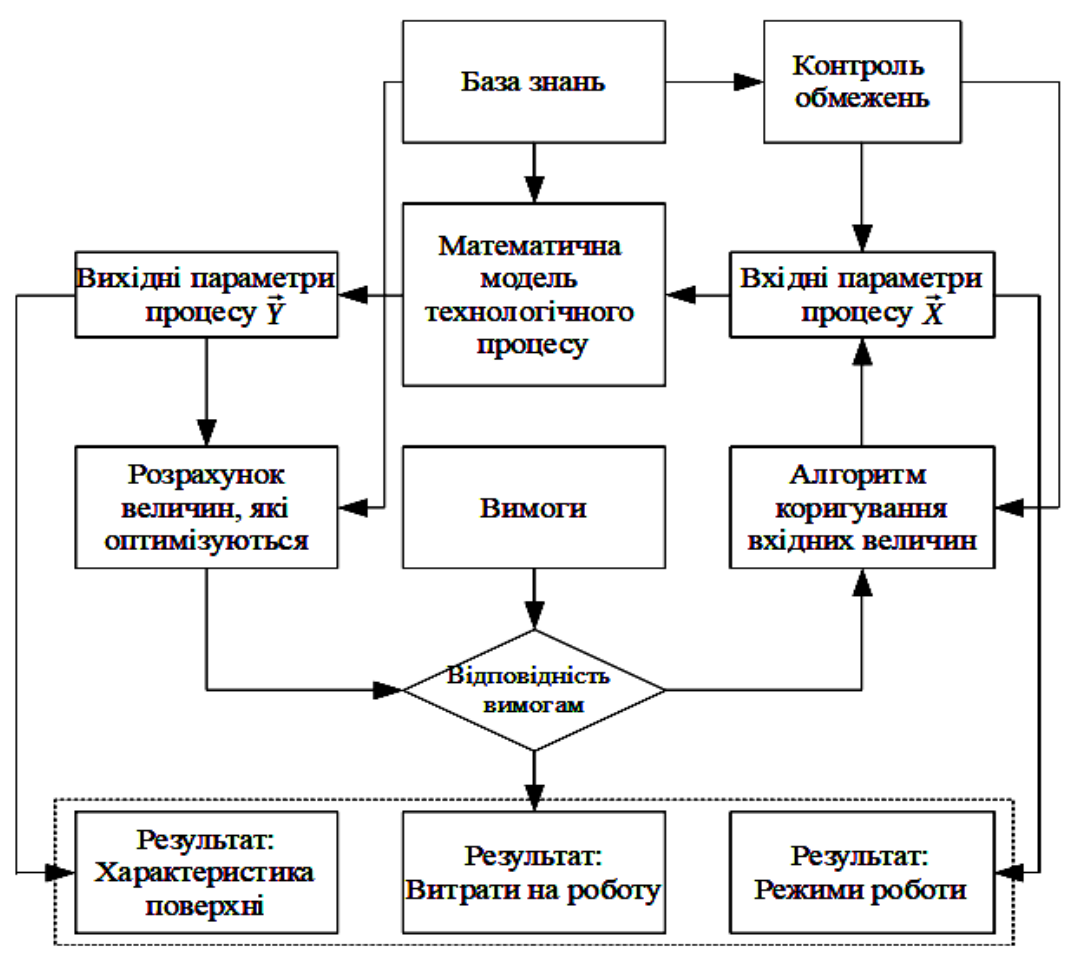

Рис. 3. Діаграма потоку інформації в реалізації ЕС оптимізації процесу відновлення та зміцнення поверхонь валів ЕДН

В результаті аналізу інформаційних потоків під час оптимізації ТП відновлення та зміцнення поверхонь ЕДН, отримано nfri інформаційні одиниці:

- базу знань, яка містить дані експериментів, допустимі діапазони вхідних даних, список вхідних параметрів, список вихідних параметрів, методи та математичне забезпечення розрахунків витрат на процес;

- систему отримання вимог до результатів відновлення та критерій (або критерії) оптимізації;

- систему пошуку екстремумів в багатовимірному просторі;

- систему перевірки на досягнення результату;

- систему виявлення “зацикленості” пошуку розв’язків, у випадках недосяжності поставлених вимог;

- систему введення неконтрольованих вхідних параметрів (в вказаній системі не використано, бо устаткування має контрольоване середовище обробки [4]);

- систему забезпечення інформаційного потоку між компонентами ЕС з врахуванням синхронізації та взаємних блокувань.

Перераховані пункти є складовими інформаційного забезпечення функціонування ЕС.

\section{Абстрактні експертні системи, їх складові}

На основі показаної інформаційної моделі ТО ЕДН, проведемо формалізацію та узагальнення інформаційної моделі на більшість ТО відновлення та зміцнення поверхонь.

Нехай маємо математичну модель ТП k відновлення поверхонь, який позначимо на основі (1):

$$
\overrightarrow{Y_{k}}=f\left(\vec{X}_{k}, \vec{V}_{k}, \vec{Z}_{k}, \vec{R}_{k}\right),
$$

де $\vec{Y}_{k} \in Y$ - кількісні значення підмножини характеристик поверхонь, яка отримана за результатами ТП k;

- $\vec{X}_{k} \in X$ - кількісні значення підмножини відомих та контрольованих параметрів окремого ТП 3 усіх доступних.

Відповідно до попередніх підмножин, позначено підмножини, які відносяться до неконтрольованих та інших вхідних параметрів (1). Відповідно до цього, з причини того, що в загальному випадку невідома кількість даних для побудови математичної моделі ТП, не можливо заздалегідь визначити методи іiі побудови. Для цього потрібно доповнити модель додатковими даними та засобами побудов математичних моделей М. Множина застосовних методів побудови математичних моделей процесу позначатиметься $\vec{M}_{k} \in M$ і буде залежною від наявного набору даних для побудови моделей (5):

$$
\vec{M}_{k}=C\left[M, \underline{\underline{y \operatorname{def}}} Y_{k}, \underline{\underline{\operatorname{def}}} X_{k}, \underline{\underline{v e f}} \underline{\underline{\operatorname{def}}}\right],
$$

де def - операція відбору відомих значень які будуть використані для побудови математичної моделі.

Таке визначення вибору множини методів побудови математичних моделей обгрунтовано тим, що при великій кількості даних можна для регресії використати методи на основі апроксимацій або нейронні мережі. При малому наборі даних вибір звужується до вибору між методом найменших ква- 
дратів, сплайнів або інтерполяційних операцій. Відповідно до цього, операція фільтрування допустимих методів (5) є необхідною, і при доповненні бази знань, методи математичного моделювання можуть змінюватися. Вибір методу з допустимих $\mathrm{F}$ може бути покладено на людину або виконуватися автоматично за заздалегідь внесеними пріоритетами. Фактично, ЕС міститиме в собі вкладену ЕС математичного моделювання та алгоритмів пошуку максимумів та мінімумів на ній. Результатом дії такої системи є готова математична модель (6):

$$
f:\left[\vec{M}_{k}, y, x, v\right],
$$

де $f$ - функція яка використана в (4).

Нерідко технологічні процеси $є$ складовими складних, багатоетапних, технологій відновлення або зміцнення поверхонь деталей.
В такому випадку поверхня під час обробки не приймає на виході значення $Y_{k}$, а відбувається перетворення властивостей поверхні $\vec{Y}_{k} \rightarrow \vec{Y}_{k+1}$, при цьому на результат можуть впливати вхідні властивості, як при шліфуванні, або можуть й не впливати, як при ЕДН.

Тому для узагальненої моделі ТП, модель (4) потрібно доповнити явно вхідними параметрами поверхні, що з врахуванням (5) та (6) надає такий вираз:

$$
\vec{Y}_{k}=F[C[M, y, x, v]]\left(\vec{X}_{k}, \vec{V}_{k}, \vec{Z}_{k}, \vec{R}_{k}, \vec{Y}_{k-1}\right)
$$

Вказані зауваження та доповнення вимагають внесення змін до діаграми руху інформації (рис. 3) в ЕС (рис. 4).

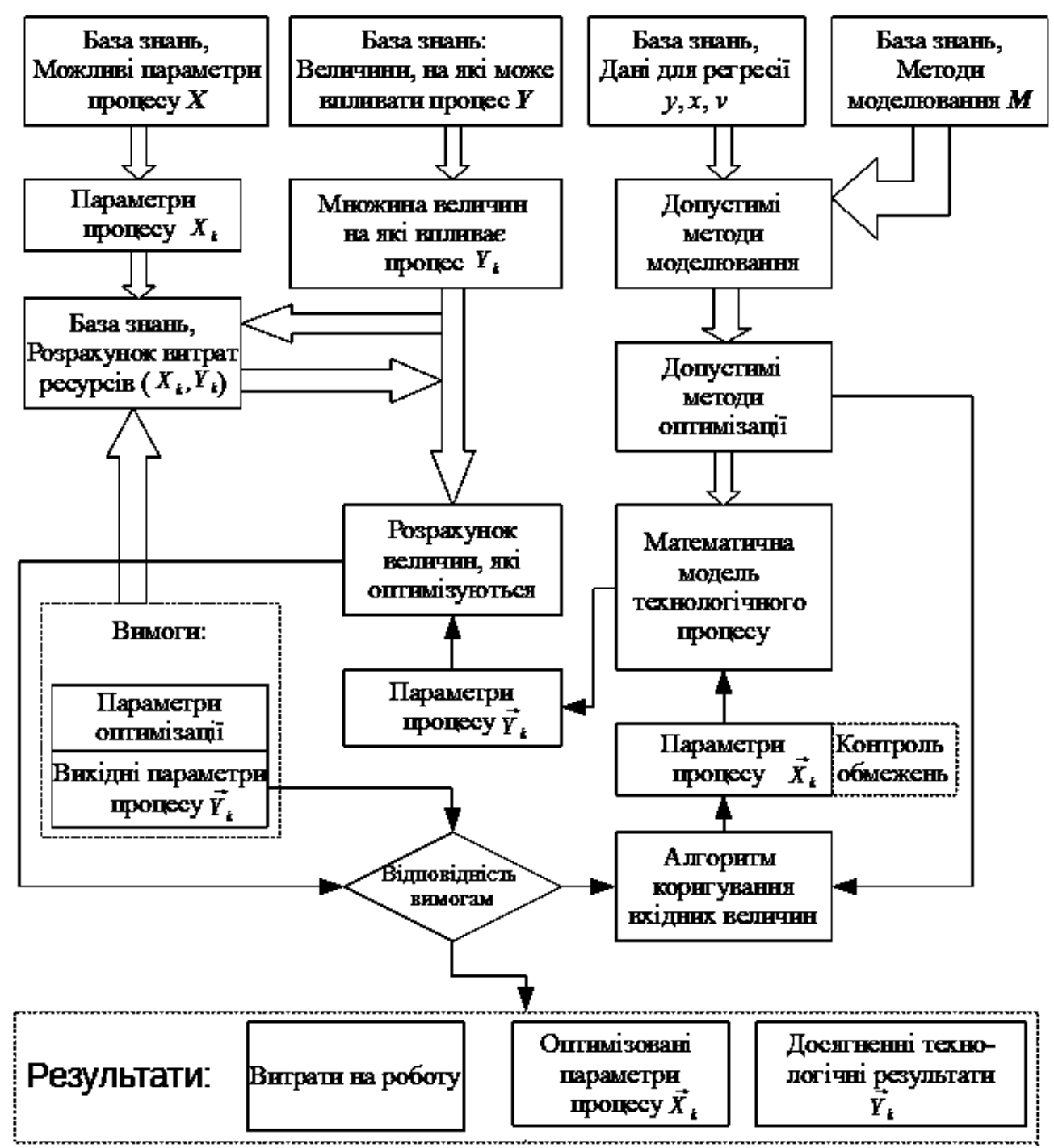

Рис. 4. Діаграма потоку інформації в реалізації узагальненої k-ї ЕС оптимізації ТП

\section{Висновки}

В роботі синтезовано абстрактний технологічний процес, визначено його властивості та методи переходу до конкретного технологічного процесу; сформульовано інформаційну модель технологічно- го процесу та методи їі отримання, що дозволило побудувати абстрактні експертні системи та їх складові для оптимізації процесу відновлення та зміцнення поверхонь деталей типу «вал» електродуговим напиленням у вигляді хмарної рекомендаційної системи як сервісу (SaaS). 
1. В.Д. Хох, С.В. Мелешко, та М.С. Якименко, «Дослідження методів побудови експертних систем», Системи управління, навігаиї̈ та зв'язку, випуск 4(40), с.48-52, 2016

2. К.І. Скрипка, та М.А. Зенкин «Експертна система автоматизованого вибору способів відновлення спрацьованих деталей», Вісник ЖДТУ. Технічні науки, № 1 (28), с. 66-68, 2004.

3. О.М. Верес, Технології підтримки прийняття рімень. Львів, Україна: Видавництво Львівської політехніки, 2013.

4. В. В. Лимаренко, «Інформаційна система підтримки рішень для автоматизації створення технологічних процесів механообробки деталей високоточного обладнання», дисертація канд. техн. наук, Національний технічний університет «Харківський політехнічний інститут», Харків, 2019

Рецензент: д-р техн. наук, проф. С. Г. Семенов, Національний технічний університет “.ХПІ”, Харків

Received (Надійшла) 11.02.2019

Accepted for publication (Прийнята до друку) 27.03.2019

\section{Експертна система оптимізації процесу відновлення та зміцнення поверхонь деталей типу «ВАЛ» електродуговим напиленням \\ Т. В. Смірнова, О. М. Дрєєв, О. А. Смірнов}

Предметом вивчення у статті $є$ побудова експертної системи оптимізації процесу відновлення та зміцнення поверхонь деталей типу «ВАЛ»електродуговим напиленням. Метою роботи $є$ побудова експертної системи оптимізації процесу відновлення та зміцнення поверхонь деталей типу «вал» електродуговим напиленням у вигляді хмарної рекомендаційної системи як сервісу (SaaS) з отримання поверхонь валів зі сталі 45 із заданими характеристиками на основі комбінації декількох технологічних процесів. Задачі: синтезувати абстрактний технологічний процес, визначити його властивості та методи переходу до конкретного технологічного процесу; сформулювати інформаційну модель технологічного процесу та методи їі отримання; побудувати абстрактні експертні системи та їх складові для оптимізації процесу відновлення та зміцнення поверхонь деталей типу «вал» електродуговим напиленням. Результатами роботи $є$ експертна система, яка включає у себе: базу знань, що містить дані експериментів, допустимі діапазони вхідних даних, список вхідних параметрів, список вихідних параметрів, методи та математичне забезпечення розрахунків витрат на процес; систему отримання вимог до результатів відновлення та критерій (або критерії) оптимізації; система пошуку екстремумів в багатовимірному просторі; систему перевірки на досягнення результату; систему виявлення “зацикленості” пошуку розв'язків, у випадках недосяжності поставлених вимог; систему введення неконтрольованих вхідних параметрів (в вказаній системі не використано, тому що устаткування має контрольоване середовище обробки); систему забезпечення інформаційного потоку між компонентами експертної системи з урахуванням синхронізації та взаємних блокувань. Висновки: наукова новизна полягає у сукупності синтезованого абстрактного технологічного процесу, визначення його властивостей та методів переходу до конкретного технологічного процесу; сформульованої інформаційної моделі технологічного процесу та методів іiї отримання, що дозволило побудувати абстрактні експертні системи та їх складові для оптимізації процесу відновлення та зміцнення поверхонь деталей типу «вал» електродуговим напиленням у вигляді хмарної рекомендаційної системи як сервісу (SaaS).

Keywords: експертна система, інформаційні процеси, прийняття рішень, поверхня, відновлення, зміцнення, сталь.

\section{Expert system of optimization of the return and strengthening of the surface of "TUBE" type detectors by electricity surface \\ T. Smirnova, O. Drieiev, O. Smirnov}

The subject of study in the article is the construction of an expert system for optimizing the process of restoration and strengthening of surfaces of parts of the type "VAL" by an electric arc spraying. The purpose of the work is to construct an expert system for optimizing the process of restoration and strengthening of surfaces of parts of the "shaft" type by electric arc spraying in the form of a cloud advisory system as a service (SaaS) for obtaining surfaces of shafts from steel 45 with given characteristics on the basis of a combination of several technological processes. Tasks: to synthesize an abstract technological process, to determine its properties and methods of transition to a specific technological process; to formulate an information model of the technological process and methods of its obtaining; to construct abstract expert systems and their components for optimization of the process of restoration and strengthening of surfaces of parts of the "shaft" type by electric arc spraying. The results of the work are an expert system, which includes: a knowledge base containing experimental data, valid input ranges, list of input parameters, list of output parameters, methods and mathematical support for process cost calculations; system for obtaining requirements for recovery results and optimization criterion (or criteria); system of search of extremums in multidimensional space; verification system to achieve the result; a system for detecting "stagnation" of the search for solutions, in cases where the requirements are not reachable; the system of input of uncontrolled input parameters (in the given system is not used, because the equipment has a controlled processing environment); a system for providing information flow between components of the expert system, taking into account synchronization and mutual interlocking. Conclusions: scientific novelty consists in the synthesis of the synthesized abstract technological process, determination of its properties and methods of transition to a specific technological process; the formulated information model of the technological process and methods of its obtaining that allowed to construct abstract expert systems and their components for optimization of the process of restoration and strengthening of surfaces of parts of the "shaft" type by electric arc spraying in the form of a cloud advisory system as a service (SaaS).

Keywords : expert system, information processes, decision making, surface, restoration, strengthening, steel. 